\title{
THE THANKSGIVING MEETING IN CINCINNATI
}

The three hundred ninth regular meeting of the Society was held at the University of Cincinnati on Friday and Saturday, December 1-2, 1933. About one hundred persons attended the meeting, among whom were the following fifty-one members of the Society:

W. E. Anderson, H. F. Archibald, W. L. Ayres, F. R. Bamforth, G. M. Bareis, I. A. Barnett, Henry Blumberg, Louis Brand, R. S. Burington, R. D. Carmichael, A. B. Coble, L. W. Cohen, L. L. Dines, H. H. Downing, J. D. Elder, Arnold Emch, L. M. Graves, Harris Hancock, E. H. Hanson, R. E. Hundley, W. R. Hutcherson, M. H. Ingraham, H. S. Kaltenborn, H. J. Kersten, J. H. Kindle, Lincoln LaPaz, C. G. Latimer, F. E. LeStourgeon, C. I. Lubin, C. C. MacDuffee, C. W. Mendel, G. M. Merriman, H. A. Meyer, C. N. Moore, M. E. Mullings, Alta Odoms, S. E. Pence, H. S. Pollard, Tibor Rad6, G. Y. Rainich, S. E. Rasor, F. W. Reed, C. E. Rhodes, G. W. Starcher, Guy Stevenson, A. H. Tappan, H. P. Thielman, Sister M. D. Thuener, O. Veblen, K. P. Williams, E. I. Yowell.

On Friday afternoon Professor R. D. Carmichael gave an address entitled Functions of exponential type. On Saturday afternoon there was a joint meeting with the American Physical Society on Spinor analysis at which Professor Otto Laporte spoke on Spinors and their significance in modern physics and Professor Oswald Veblen spoke on Spinor analysis. There was also a large amount of discussion at this meeting.

Friday evening a dinner was held at the Hotel Sinton-St. Nicholas. About fifty persons attended thedinner. Professor Harris Hancock of the University of Cincinnati welcomed the visiting mathematicians, and President Coble responded to his welcome expressing the pleasure of the group in meeting at Cincinnati.

Saturday noon the mathematicians and physicists met at a joint luncheon at the Mecklenburg Restaurant. About seventyfive persons attended this luncheon.

President A. B. Coble and Professor C. N. Moore presided at the meetings on Friday afternoon, President Coble and Professor L. L. Dines on Saturday morning, and Professor J. H. Van Vleck at the joint session Saturday afternoon.

A very pleasant feature of the meeting was the tea served by the ladies of the University of Cincinnati to the visiting mathematicians and physicists on Friday afternoon. 
The titles of papers read at the meeting follow. Those whose abstract numbers are followed by $t$ were read by title. Mr. P. M. Pepper was introduced by Professor C. N. Moore, Mr. H. E. Vaughan by Professor W. L. Ayres, Miss Marjorie Leffler by Professor Tibor Radó, Mr. W. C. Mitchell by Professor C. N. Moore, and Mr. E. S. Akeley by Professor Cornelius Lanczos.

1. A classification of plane cubic curves under the affine group by means of arithmetic invariants, by Professor R. S. Burington. (Abstract No. 40-1-5.)

2. Some remarkable sextic space curves, by Professor Arnold Emch. (Abstract No. 39-11-301.)

3. Affine-polygenic functions, by Mr. P. M. Pepper. (Abstract No. 40-1-6.)

4. A significant vector in the theory of surfaces, by Professor Louis Brand. (Abstract No. 40-1-7.)

5. On the units in a cyclic field. by Professor C. G. Latimer. (Abstract No. 40-1-8.)

6. Some theorems on connected sets, by Mr. H. E. Vaughan. (Abstract No. 40-1-9.)

7. On the relation between local connectivity and another property, by Professor W. L. Ayres. (Abstract No. 40-1-10.)

8. On the relative stability of the median and arithmetic mean, by Professor H. S. Pollard. (Abstract No. 40-1-11.)

9. The first and second variations of an n-tuple integral in the case of variable limits, by Professor H. A. Simmons. (Abstract No. 39-11-303-t.)

10. A determination of all normal division algebras of degree 4 over $F$ of characteristic 2, by Professor A. A. Albert. (Abstract No. 39-11-300-t.)

11. On certain imprimitive fields of degree $p^{2}$ over $P$ of characteristic $p$, by Professor A. A. Albert. (Abstract No. 39-11-299-t.)

12. Normal division algebras over a modular field, by Professor A. A. Albert. (Abstract No. 39-11-302-t.)

13. The flexure problem for rectangular beams with slits, by Professor D. F. Gunder. (Abstract No. 39-11-298-t.)

14. An existence theorem for generalized pfaffian systems, by Professor J. M. Thomas. (Abstract No. 39-11-297-t.)

15. Note on potential theory in n-space, by Professor J. J. L. Hinrichsen. (Abstract No. 39-11-321-t.) 
16. On measures of contingency (preliminary report), by Professor F. M. Weida. (Abstract No. 39-11-324-t.)

17. On a problem of Knaster and Zarankiewicz, by Professor J. H. Roberts. (Abstract No. 39-11-323-t.)

18. Algebraic functions of Stepanoff almost periodic, by Dr. R. H. Cameron (National Research Fellow). (Abstract No. 40-1-12-t.)

19. On a lemma of Fejér, by Professor Lincoln LaPaz. (Abstract No. 40-1-13.)

20. A lemma in potential theory (preliminary report), by Miss Marjorie Leffler. (Abstract No. 39-11-322.)

21. Singularities on maps of surfaces, by Professor G. Y. Rainich. (Abstract No. 40-1-14.)

22. Transformation of an integro-differential equation by means of a Volterra transformation, by Professor I. A. Barnett. (Abstract No. 40-1-15.)

23. Some properties of Stieltjes integrals, by Mr. H. S. Kaltenborn. (Abstract No. 40-1-16.)

24. On convergence factors for double series that are summable of non-integral orders, by Professor C. N. Moore. (Abstract No. 40-1-17.)

25. Borel-Sannia summability for double series, by Mr. W. C. Mitchell. (Abstract No. 39-11-320.)

26. On the Cesdro mean of double Fourier series, by Miss Alta Odoms. (Abstract No. 40-1-18.)

27. An invariantive characterization of quadratic differential forms, by Dr. E. S. Akeley. (Abstract No. 40-1-19.)

28. A new proof of a theorem of Denjoy, Young, and Saks, by Mr. E. H. Hanson. (Abstract No. 40-1-20.)

29. The equivalence of $n$-tuples of matrices (preliminary report), by Professor O. E. Brown. (Abstract No. 40-1-21-t.)

M. H. Ingraham, Associate Secretary 